\title{
Alcohol, oxidative stress and free radical damage
}

\author{
Emanuele Albano \\ Department of Medical Sciences, University of 'A. Avogadro' East Piedmont, Novara, Italy
}

\begin{abstract}
The involvement of free radical mechanisms in the pathogenesis of alcoholic liver disease (ALD) is demonstrated by the detection of lipid peroxidation markers in the liver and the serum of patients with alcoholism, as well as by experiments in alcohol-feed rodents that show a relationship between alcohol-induced oxidative stress and the development of liver pathology. Ethanol-induced oxidative stress is the result of the combined impairment of antioxidant defences and the production of reactive oxygen species by the mitochondrial electron transport chain, the alcohol-inducible cytochrome P450 (CYP) 2E1 and activated phagocytes. Furthermore, hydroxyethyl free radicals (HER) are also generated during ethanol metabolism by CYP2E1. The mechanisms by which oxidative stress contributes to alcohol toxicity are still not completely understood. The available evidence indicates that, by favouring mitochondrial permeability transition, oxidative stress promotes hepatocyte necrosis and/or apoptosis and is implicated in the alcohol-induced sensitization of hepatocytes to the pro-apoptotic action of TNF- $\alpha$. Moreover, oxidative mechanisms can contribute to liver fibrosis, by triggering the release of pro-fibrotic cytokines and collagen gene expression in hepatic stellate cells. Finally, the reactions of HER and lipid peroxidation products with hepatic proteins stimulate both humoral and cellular immune reactions and favour the breaking of self-tolerance during ALD. Thus, immune responses might represent the mechanism by which alcohol-induced oxidative stress contributes to the perpetuation of chronic hepatic inflammation. Together these observations provide a rationale for the possible clinical application of antioxidants in the therapy for ALD.
\end{abstract}

Ethanol: Lipid peroxidation: Free radicals: Immune response: Antioxidants

It is now well accepted that the progression of liver injury consequent to chronic alcohol abuse is a multifactorial event that involves a number of genetic and environmental factors. Among these factors there is a growing interest in the role of free radical-mediated oxidative stress. The involvement of oxidative injury in ethanol toxicity was first proposed in the early 1960s by Di Luzio (1963) and subsequently supported by a number of experimental studies showing that ethanol promotes the formation of a variety of free radical intermediates (oxygen-derived radicals, 1-hydroxyethyl radicals $\left(\mathrm{CH}_{3} \mathrm{C}^{\bullet} \mathrm{HOH}\right.$; HER), NO, lipid-derived radicals) by several cell types, including hepatocytes, Kupffer cells, endothelial cells and infiltrating inflammatory leucocytes (for reviews, see Nordmann et al. 1992; Albano, 2002). However, the most convincing evidence to clarify the role of oxidative damage in the pathogenesis of alcohol-induced liver injury has been obtained using a procedure in which alcohol is fed enterally to rodents (Tsukamoto et al. 1985). Using this experimental model Nanji and coworkers (Nanji \& French, 1989; Nanji et al. 1994a) have shown that rats fed ethanol in combination with diets rich in unsaturated fatty acids from maize or fish oils develop liver damage. This outcome is associated with an increase in the hepatic content of lipid peroxidation products (Nanji et al. 1994a,b; Polavarapu et al. 1998), suggesting that the generation of aldehydic end products of the peroxidative breakdown of PUFA promotes ethanol toxicity. Interestingly, after 6 weeks of ethanol administration the replacement of fish oil with poorly-oxidizable palm oil or with medium-chain triacylglycerols lowers lipid peroxidation and ameliorates already established liver damage (Nanji et al. 1995b). In

\footnotetext{
Abbreviations: ALD, alcoholic liver disease; CYP, cytochrome P450; GSH, glutathione; HSC, hepatic stellate cells; HER, 1-hydroxyethyl radicals; iNOS, inducible NO synthetase; MDA, malondialdehyde; MPT, mitochondrial permeability transition; mtGSH, mitochondrial GSH; ROS, reactive oxygen species; SOD, superoxide dismutase.

Corresponding author: Professor Emanuele Albano, fax + 390321 620421, email albano@med.unipmn.it
} 
accordance with these findings, several other studies have demonstrated that supplementation with different antioxidants and free radical scavengers reduces hepatic injury in alcohol-fed rodents (Nanji et al. 1994b; Albano et al. 1996; Sadrzadeh \& Nanji, 1998; Arteel, 2003; Ronis et al. 2005). The relevance of these observations to human alcoholic liver disease (ALD) is demonstrated by several clinical studies showing that serum markers of lipid peroxidation, such as conjugated dienes, malondialdehyde (MDA), 4-hydroxynonenal and F2-isoprostanes, are increased in patients with ALD (Clot et al. 1994; Aleynik et al. 1998; Meager et al. 1999). Moreover, immunohistochemical analysis of liver biopsies from patients with alcoholism reveals that proteins adducted by lipid peroxidation products are localized in the areas of liver fatty infiltration, focal necrosis and fibrosis (Niemelä et al. 1994).

The present paper will review the most recent insights into the mechanisms responsible for ethanol-induced free radical formation and the contribution of oxidative stress to liver injury by alcohol.

\section{Ethanol and free radical formation}

\section{Formation of reactive oxygen species}

The formation of reactive oxygen species (ROS) such as the superoxide anion $\left(\mathrm{O}_{2}^{-}\right)$and $\mathrm{H}_{2} \mathrm{O}_{2}$ represents an important cause of oxidative injury in many diseases associated with free radical formation. In the presence of trace amounts of transition metals (most frequently $\mathrm{Fe}$ ) $\mathrm{O}_{2}^{-}$and $\mathrm{H}_{2} \mathrm{O}_{2}$ generate highly-reactive hydroxyl radicals, which are then responsible for the oxidation of biological constituents. Several enzymic systems, including the cytochrome P450 (CYP) 2E1-dependent microsomal monoxygenase system, the mitochondrial respiratory chain and the cytosolic enzymes xanthine oxidase and the aldehyde oxidases have been implicated as sources of $\mathrm{O}_{2}^{-}$and $\mathrm{H}_{2} \mathrm{O}_{2}$ in parenchymal cells during ethanol intoxication (Albano, 2002).

CYP2E1-dependent monoxygenase activity increases by 10-20-fold in alcohol-treated rodents (Ronis et al. 1996). In human subjects the determination of CYP2E1 activity by measuring the oxidation of the myorelaxant drug chlorzoxazone reveals an appreciable CYP2E1 induction not only in alcohol abusers (Girre et al. 1994), but also in moderate alcohol consumers (Liangpunsakul et al. 2005). CYP2E1 has an especially high rate of NADPH oxidase activity, which leads to the production of large quantities of $\mathrm{O}_{2}^{-}$and $\mathrm{H}_{2} \mathrm{O}_{2}$. In liver microsomes from both human subjects and alcohol-fed rodents the CYP2E1 content is positively correlated with NADPH oxidase activity and lipid peroxidation (for review, see Ronis et al. 1996). Increased ROS production is also evident in HepG2 hepatoma cells stably transfected with the CYP2E1 gene (Caro $\&$ Cederbaum, 2004). Thus, the high efficiency of CYP2E1 in reducing $\mathrm{O}_{2}$ to $\mathrm{O}_{2}^{-}$and $\mathrm{H}_{2} \mathrm{O}_{2}$ could be regarded as one of the key factors contributing to oxidative stress during chronic exposure to alcohol. Consistently, experiments performed using rats enterally fed alcohol (Albano et al. 1996; Fang et al. 1998; Gouillon et al. 2000) have demonstrated that the induction of CYP2E1 by ethanol is associated with the stimulation of lipid peroxidation, while compounds interfering with CYP2E1 expression reduce oxidative stress and hepatic damage. These findings are in partial contrast with the observation that CYP2E1-knockout mice are not protected from alcohol toxicity (Kono et al. 1999). This discrepancy can be explained, since in ethanol-fed mice CYP2E1 represents $<5 \%$ of the total hepatic CYP content (Bardag-Gorce et al. 2000). Thus, the contribution of CYP2E1 to alcohol toxicity might be blunted by other factors. Nevertheless, more recent studies (Bardag-Gorce et al. 2000; Bradford et al. 2005) have shown that after ethanol treatment both carbonyl groups and oxidized DNA products are actually lower in CYP2E1null mice as compared with CYP2E1-expressing mice. Furthermore, chronic enteral administration of ethanol to CYP2E1 transgenic mice, which overexpress CYP2E1 by about 2-fold, causes more liver pathology and transaminase release than in naïve mice (Morgan et al. 2002).

The oxidation of mitochondrial proteins and DNA is a common feature of both acute and chronic ethanol exposure (Hoek et al. 2002). An enhanced electron leakage from complexes I and III of the mitochondrial respiratory chain along with a stimulation of NADH shuttling to the mitochondria have been proposed to account for the increase in $\mathrm{O}_{2}^{-}$production observed in isolated rat hepatocytes incubated acutely with ethanol (Bailey \& Cunningham, 2002). Conversely, an impaired synthesis of mitochondria-encoded constituents of the respiratory chain, particularly cytochrome $b$, consequent to oxidative mitochondrial DNA damage is probably responsible for the enhanced production of ROS observed in liver mitochondria from rats treated chronically with ethanol (Bailey \& Cunningham, 2002). An additional mechanism contributing to the mitochondrial formation of ROS might be represented by the interaction between complexes II and III and $\mathrm{N}$-acetyl-D-sphingosine (C2-ceramide) released by hepatocytes in response to TNF- $\alpha$ (Garcia-Ruiz et al. 2000). Furthermore, Neve \& Ingelman-Sundberg (2001) have described a form of CYP2E1 that lacks the hydrophobic part of the $\mathrm{NH}_{2}$ terminus, is localized in the matrix of liver mitochondria and might contribute to causing alcohol-induced mitochondrial oxidative damage.

Experiments using the enteral nutrition model (Hines \& Wheeler, 2004) have shown that the activation of Kupffer cells in response to circulating bacterial endotoxins stimulates inflammatory reactions within the liver. Moreover, in alcohol abusers as well as in alcohol-fed rodents chronic ethanol intake increases the production of CXC chemokines (chemokines with paired cysteine residues separated by a different amino acid; IL-8 in human subjects and cytokine-induced neutrophil chemoattractant in rats) and macrophage chemotatic protein-1, which promote hepatic leucocyte infiltration by up regulating the expression of CD18 adhesion molecule in neutrophils and its counter receptor intracellular adhesion molecule 1 in endothelial cells (Bautista, 2002). These events account for the increased hepatic sequestration of granulocytes associated with advanced ALD and for the priming of neutrophils to $\mathrm{O}_{2}^{-}$production (Bautista, 2002). Accordingly, liver depletion of Kupffer cells with $\mathrm{GdCl}_{3}$ lowers the hepatic 
production of $\mathrm{O}_{2}^{-}$in the recovery period after $12 \mathrm{~h}$ of continuous ethanol infusion (Bautista \& Spitzer, 1996) and reduces both liver injury and oxidative stress markers in rats subjected to chronic enteral feeding of alcohol (Arteel, 2003). Similar protection is also evident in mice deficient in intracellular adhesion molecule 1 (Kono et al. 2001b) or the phagocyte NADPH oxidase activity (p47phox-knockout mice; Kono et al. 2000). However, more recent investigations that have measured oxidative DNA damage as an index of intracellular oxidative stress (Bradford et al. 2005) have shown that the extent of DNA oxidation induced by alcohol administration is comparable in both p47phox-knock-out and naïve mice, whereas CYP2E1-null mice are instead protected from such damage. Together these results indicate the contribution of both intracellular and extracellular sources of ROS to ethanol-induced oxidative stress. However, ROS produced by CYP2E1 appear to be more important in causing intracellular oxidative injury than ROS originating from activated phagocytes (Bradford et al. 2005).

\section{Role of iron in ethanol-induced oxidative stress}

Alcohol abuse in human subjects is often associated with impaired utilization and/or increased deposition of $\mathrm{Fe}$ in the liver (Irving et al. 1988). Moreover, a recent survey (Ioannou et al. 2004) has demonstrated that even moderate alcohol consumption increases the risk of hepatic $\mathrm{Fe}$ overload. Although the presence of Fe, particularly of lowmolecular-weight non-protein Fe complexes, exacerbates oxidative damage by ethanol (Caro \& Cederbaum, 2004) and primes hepatic macrophages to produce ROS and proinflammatory cytokines (Tsukamoto et al. 1999), it is not yet clear how ethanol favours $\mathrm{Fe}$ accumulation in the liver and the actual role of $\mathrm{Fe}$ in the progression of ALD. It has been proposed that oxidative modifications of cytosolic Fe regulatory protein 1 might cause the inappropriate repression of ferritin synthesis and the concomitant stimulation of transferrin receptor synthesis. This outcome would lead to an increased Fe uptake combined with an impaired capability of hepatocytes to store Fe (Rouault, 2003). In support of this hypothesis, preliminary data from Suzuki et al. (2004) show that the incubation of isolated rat hepatocytes with ethanol $(25 \mathrm{mmol} / \mathrm{l})$ increases the expression of transferrin receptor and enhances transferrin uptake. The actual contribution of $\mathrm{Fe}$ to alcohol toxicity also awaits further investigation. Dietary Fe supplementation worsens liver pathology and lipid peroxidation in the enteral-alcohol feeding model (Tsukamoto et al. 1995). However, in the same experimental model the liver content of low-molecular-weight $\mathrm{Fe}$ is decreased (Rouach et al. 1997) or unchanged (Kamimura et al. 1992). Conflicting results have also been obtained using $\mathrm{Fe}$ chelators, as the administration of the oral Fe chelator 1,2dimethyl-3-hydroxypyrid-4-one in combination with chronic enteral feeding of ethanol reduces non-haem-Fe levels, lipid peroxidation and fat accumulation, whereas the long-acting parenteral Fe chelator hydroxyethylstarchdesferoxamine has no effect (Sadrzadeh et al. 1994b, 1997).
Nitric oxide and alcohol-induced oxidative injury

$\mathrm{NO}$ is a N-centred free radical produced from L-arginine by constitutive NO synthetase and inducible NO synthetase (iNOS) enzymes. In hepatocytes and endothelial and Kupffer cells membrane-bound constitutive NO synthetase produces pulses of $\mathrm{NO}$ for short periods in response to specific stimuli, and the NO so formed mediates intra- and intercellular signalling (Li \& Billiar, 1999). Once stimulated by cytokines or endotoxins the same cells respond with the activation of cytosolic iNOS, which leads to the continuous formation of large amounts of NO (Li \& Billiar, 1999). The reaction of NO with $\mathrm{O}_{2}^{-}$leads to the formation of highly-reactive peroxynitrite $\left(\mathrm{ONOO}^{-}\right)$, which can inactivate several enzymes and impair mitochondrial functions (Beckman \& Koppenol, 1996). Chamulitrat \& Spitzer (1996) have shown that in rats chronically exposed to ethanol the generation of NO triggered by the infusion of endotoxins is 3-fold higher when compared with that of naïve animals. Furthermore, iNOS-knock-out mice are protected against the oxidative stress, tyrosine nitration and hepatic injury induced by chronic enteral feeding of alcohol (Arteel, 2003). A comparable protection is also given in wild-type mice by treatment with $\mathrm{N}$-(3-aminomethyl)benzyl-acetamindine $(1400 \mathrm{~W})$, a highly-selective iNOS inhibitor (McKim et al. 2003), suggesting the possible contribution of NO generated by iNOS to alcoholrelated oxidative stress. On the other hand, the inhibition of $\mathrm{NO}$ formation enhances $\mathrm{O}_{2}^{-}$release by Kupffer cells (Bautista \& Spitzer, 1994). Moreover, the stimulation of NO production in hepatocytes increases their resistance to ethanol-induced oxidative stress by lowering the intracellular low-molecular-weight $\mathrm{Fe}$ content (Sergent et al. 1997). This protective action of NO is consistent with the observation that treatment with the non-selective NO inhibitor N-nitro-L-arginine methyl ester worsens alcoholrelated liver damage (Nanji et al. 1995a). These contrasting results might reflect the different effects exerted by NO associated with the timing, the location and the rate of its production. Nonetheless, the actual role of $\mathrm{NO}$ in the pathogenesis of oxidative stress induced by alcohol awaits further investigation.

\section{Ethanol-derived free radicals}

The use of electron-spin-resonance spectroscopy in combination with a spin-trapping technique has revealed that ethanol oxidation by CYP2E1 results in the formation of a free radical metabolite identified as HER (Albano et al. 1994). In addition, it has been reported that the in vivo trapping of HER is decreased by Kupffer cell destruction with $\mathrm{GdCl}_{3}$ (Knecht et al. 1995) as well as in both NADPH oxidase- and iNOS-knock-out mice (Kono et al. 2000; McKim et al. 2003). These findings suggest the possibility that the interaction of ethanol with $\mathrm{ONOO}^{-}$might also contribute to the formation of HER. However, the actual importance of these observations requires further investigation.

Although HER are produced by rat liver microsomes at a rate ten times lower than the rate of ethanol conversion to acetaldehyde (Stoyanovsky \& Cederbaum, 1998), their 
high reactivity towards ascorbic acid, glutathione (GSH), $\alpha$-tocopherol and DNA (Nakao \& Augusto, 1998; Stoyanovsky et al. 1998) might be relevant in relation to alcohol toxicity. When rat liver microsomes are incubated with NADPH and $\left[{ }^{14} \mathrm{C}\right]$ ethanol the HER residues account for the majority of the radioactivity that can be recovered covalently bound to microsomal proteins (Albano et al. 1993). Immunoblots using antibodies raised against HERprotein adducts have demonstrated the binding of HER to at least four microsomal proteins, including CYP2E1 (Clot et al. 1996). The formation of HER-CYP2E1 adducts also occurs in vivo following both acute and chronic ethanol intoxication (Clot et al. 1996). One of the consequences of the alkylation by HER of liver proteins is the stimulation of an immune response characterized by the generation of antibodies specifically recognizing HER-derived epitopes (Moncada et al. 1994). These antibodies are detectable in the sera of both chronically ethanol-fed rats (Albano et al. 1996) and patients with ALD (Clot et al. 1995). Human anti-HER IgG recognize as antigen several HER-modified liver microsomal proteins and, particularly, HER-CYP2E1 adducts (Clot et al. 1996). This finding demonstrates that in human liver HER are mostly generated as a result of CYP2E1-dependent ethanol oxidation. Consistently, in both rats and human subjects the presence of anti-HER antibodies is closely correlated with CYP2E1 activity (Albano et al. 1996; Dupont et al. 1998). In particular, a minority of heavy drinkers who do not display CYP2E1 induction, when assayed by the chlorzoxazone oxidation test, have titres of anti-HER IgG comparable with those of non-drinking controls and lower than those of drinkers with normally-induced CYP2E1 activity (Dupont et al. 1998).

\section{Lowering of antioxidant defences and ethanol-induced oxidative stress}

The possible contribution of impaired antioxidant defences to ethanol-induced oxidative stress has been extensively investigated. Early studies have shown that a decrease in the liver content of reduced GSH, independent of nutritional status or the extent of liver disease, is a common feature in ethanol-fed animals as well as in patients with alcoholism (for review, see Albano, 2002). The importance of GSH homeostasis in preventing alcohol-mediated oxidative injury is supported by the observation that the stimulation of GSH re-synthesis in rats by supplementation with either of the GSH precursors L-2-oxothiazolidine-4carboxylic acid or $\mathrm{N}$-acetylcysteine prevents liver injury in the enteral alcohol model (Iimuro et al. 2000; Ronis et al. 2005). Although chronic alcohol intake does not appreciably affect the hepatocyte cytosolic GSH content, it lowers the mitochondrial GSH (mtGSH) content by 50-85\% (Fernandez-Checa et al. 1991; Hirano et al. 1992). Such an effect is more evident in the centrilobular hepatocytes (Garcia-Ruiz et al. 1994) and precedes the development of mitochondrial dysfunctions and lipid peroxidation (Hirano et al. 1992; Garcia-Ruiz et al. 1994). The selective depletion of the mtGSH pool is the consequence of a defect in GSH transport from the cytosol to the mitochondrial matrix (Fernandez-Checa \& Kaplowitz, 2005). According to a recent report (Coll et al. 2003) a decreased fluidity of mitochondrial membranes associated with cholesterol accumulation interferes with the activity of the 2-oxoglutarate carrier as well as that of another, as yet unidentified, high-affinity GSH carrier. The action of ethanol on mtGSH homeostasis might play an important role in the development of ALD, as it favours oxidative mitochondrial damage and impairs hepatocyte tolerance to TNF- $\alpha$ (Fernandez-Checa \& Kaplowitz, 2005).

Vitamin E ( $\alpha$-tocopherol) plays an important role as the main lipid-soluble antioxidant in the liver. In both human subjects and rodents chronic alcohol intake decreases liver and plasma levels of vitamin E, and the lowering of the $\alpha$-tocopherol levels is inversely correlated with the detection of lipid peroxidation markers (Bell et al. 1992; Clot et al. 1994; Sadrzadeh et al. 1994a; Rouach et al. 1997). The mechanisms responsible for the lowering of vitamin $\mathrm{E}$ associated with alcohol intake have not yet been completely elucidated. Liver microsomes from ethanol-fed rats show a decrease in $\alpha$-tocopherol: $\alpha$-tocopheryl quinone (the main oxidation product of $\alpha$-tocopherol; Kawase et al. $1989)$, suggesting that an increased oxidation of $\alpha$-tocopherol might be responsible for the lowering of hepatic vitamin E. Although vitamin E-deficient rats have an increased susceptibility to alcohol toxicity (Sadrzadeh et al. 1994a), $\alpha$-tocopheryl acetate supplementation fails to protect against liver injury (Sadrzadeh et al. 1995). This discrepancy might be explained by the poor bioavailability of some tocopheryl esters in rodents or by ethanol interfering with the enteral absorption of vitamin E. It is noteworthy that when alcohol feeding is discontinued the administration of vitamin $\mathrm{E}$ contributes to a reduction in the severity of hepatic lesions (Nanji et al. 1996). However, a recent randomized placebo-controlled clinical trial of patients with mild or moderate alcoholic hepatitis (Mezey et al. 2004) has not confirmed a marked effect of vitamin E supplementation in human subjects.

Several studies have investigated the effects of ethanol on the enzymes involved in the detoxification of ROS or lipid peroxidation products. However, the results are rather inconclusive (Nordmann et al. 1992). More recent investigations using the enteral alcohol model (Rouach et al. 1997; Polavarapu et al. 1998) have shown a marked decline in both the enzymic activity and the immunoreactive protein concentrations of liver $\mathrm{Cu}, \mathrm{Zn}$ superoxide dismutase (SOD; SOD-1), catalase and GSH peroxidase. The changes in these ROS enzyme activities are inversely correlated with the extent of both lipid peroxidation and hepatic injury (Polavarapu et al. 1998). Interestingly, the increase in mRNA expression for both liver GSH peroxidase and catalase is appreciable in the same experimental model (Nanji et al. 1995b), suggesting that ethanol might interfere at the post-transcriptional level with the synthesis of antioxidant enzymes or might stimulate their intracellular degradation. A further insight into the role of SOD in alcohol toxicity has been derived from the use of SOD-1knock-out mice that show increased lipid peroxidation, nitrotyrosine accumulation, extensive centrilobular necrosis and inflammation with moderate ethanol consumption (Kessova et al. 2003). Conversely, rodents over-expressing 
SOD-1 or the mitochondrial form Mn-SOD (SOD-2) are protected against the liver injury associated with enteral administration of a large amount of alcohol (Wheeler et al. $2001 a, b)$. Ebselen, an organoselenium compound that mimics GSH peroxidase activity (Kono et al. 2001a), also protects against ethanol toxicity and oxidative stress. About $25 \%$ of Caucasians carry a genetic polymorphism that causes an Ala16Val substitution in the leader amino acid sequence that is responsible for the mitochondrial localization of SOD-2. Although the Ala-SOD-2 variant might translocate to the mitochondria less efficiently than the Val-SOD-2 variant (Sutton et al. 2003), a study performed in 281 patients with advanced ALD and 218 heavy drinkers without liver disease or with steatosis only (Stewart et al. 2002) does not show any prevalence of SOD-2 polymorphisms in ALD. Moreover, neither the severity of liver injury nor the detection of oxidative stress markers is increased in Ala-SOD-2 homozygotes. Similarly, a large case-control survey (Brind et al. 2004) has failed to confirm any association between the susceptibility to ALD and several polymorphisms of GSH S-transferase isoenzymes. Altogether, these latter results cast some doubt on the actual importance of alcohol-induced changes in liver antioxidant enzymes to human pathology.

\section{Mechanisms of free radical damage in alcoholic liver disease}

The histological features of human ALD include a variety of lesions comprising macro- or microvesicular steatosis, ballooning degeneration of hepatocytes, hyaline necrosis, Mallory's bodies, inflammatory infiltrates and various extents of fibrosis up to cirrhosis (Ishak et al. 1991). In recent years the contribution of oxidative damage to causing some of the histological lesions associated with ALD has been discerned from experimental studies showing a positive correlation between the extent of alcohol-induced liver pathology and the detection of oxidative stress markers (Kamimura et al. 1992; Nanji et al. 1994a,b; Albano et al. 1996; Rouach et al. 1997; Polavarapu et al. 1998). Moreover, in animal studies supplementation with antioxidants or treatments that moderate oxidative stress have been reported to lower the extent of focal necrosis and inflammation, and in some cases to ameliorate steatosis (Nanji et al. 1994b; Sadrzadeh et al. 1994b; Albano et al. 1996; Sadrzadeh \& Nanji, 1998; Arteel, 2003; Ronis et al. 2005). However, the mechanisms by which oxidative stress contributes to the development of the histological lesions associated with ALD are still poorly understood.

\section{Oxidative mechanisms and mitochondrial damage by ethanol}

Morphological and functional abnormalities of mitochondria represent one of the earliest manifestations of hepatocyte injury by alcohol (Ishak et al. 1991). As discussed earlier, ethanol promotes ROS formation in the mitochondria and causes a selective decrease in mtGSH content that makes these organelles more susceptible to oxidative damage (Fernandez-Checa \& Kaplowitz, 2005). The loss of mtGSH during chronic ethanol feeding precedes the impairment of ATP synthesis, which in rats can be partially prevented by restoring mtGSH by supplementation with S-adenosyl-L-methionine (Fernandez-Checa \& Kaplowitz, 2005). Consistently, ethanol-stimulated lipid peroxidation has been linked to the impairment of mitochondrial oxidative phosphorylation and the appearance of megamitochondria (Matsuhashi et al. 1998). Mitochondria obtained from both acute and chronic alcohol-treated rats show oxidative modifications of mitochondrial DNA (Hoek et al. 2002). Single or multiple deletions of mitochondrial DNA are also 8-fold more frequent in the liver of patients with alcoholism as compared with age-matched controls (Mansouri et al. 1997). These alterations are probably responsible for the reduction in mitochondriallyencoded subunits of the electron transport chain observed in experimental animals following chronic ethanol treatment, and together with the alkylation of cytochrome $c$ oxidase by lipid peroxidation products they contribute to the impairment of hepatic respiratory activity caused by alcohol (Bailey \& Cunningham, 2002). Factors affecting the efficiency of NADH oxidation by the mitochondria have also been proposed to contribute to the metabolic imbalances responsible for hepatic steatosis (Fromenty \& Pessayre, 1995). Supporting this view, mitochondrial DNA deletions show a very high prevalence (about $85 \%$ of the cases) in patients with alcoholism who have hepatic microvesicular steatosis (Fromenty et al. 1995; Mansouri et al. 1997), which is a lesion that is ascribed to impaired mitochondrial $\beta$-oxidation of fatty acids (Fromenty \& Pessayre, 1995). Although supplementation with antioxidants such as ebselen, polyphenolic extracts or allopurinol (Arteel, 2003), but not with the 21-aminosteroid, tirilazad mesylate and $\mathrm{N}$-acetlycysteine (Sadrzadeh \& Nanji, 1998; Ronis et al. 2005), ameliorates the fat accumulation induced by enteral feeding of alcohol, the mechanisms involved have not been clarified. The observation that mice deficient in TNF receptor 1 or endotoxin binding-signalling molecules develop less steatosis than wild-type animals (Arteel, 2003) suggests the possible involvement of oxidative mechanisms in the signals leading to Kupffer cell activation by endotoxins and/or in the metabolic effects of TNF- $\alpha$ (Dandona et al. 2004). Nonetheless, it cannot be excluded that oxidative stress might also contribute to the effects of ethanol on the regulation of lipid metabolism by either the PPAR $\alpha$ or the sterol regulatory element-binding protein 1 (You \& Crabb, 2004).

The induction of oxidative stress within liver mitochondria is associated with the collapse of mitochondrial membrane potential and the onset of mitochondrial permeability transition (MPT) (Hoek et al. 2002). MPT is characterized by the opening of a megachannel in the mitochondrial membrane as a result of the assembly of a protein complex that includes a voltage-dependent anion channel, an adenine nucleotide translocator and cyclophillin D (Bernardi et al. 2001). According to Adachi et al. (2004) ethanol-induced oxidative stress promotes MTP by favouring the translocation to the mitochondria of the proapoptotic factor Bax that forms a complex with a voltagedependent anion channel. Extensive MPT leads to mitochondrial swelling as a result of the influx of ions and 
water, and is critical in the onset of hepatocyte death by necrosis. In addition, by promoting the permeabilization of the outer mitochondrial membrane MPT triggers the release of cytochrome $\mathrm{c}$ and the induction of apoptosis (Green \& Kroemer, 2004). Ethanol addition to HepG2 cells over-expressing the human CYP2E1 gene promotes the collapse of mitochondrial membrane potential, MPT and apoptosis, which can be prevented by CYP2E1 inhibitors and antioxidants, as well as by the MTP inhibitor cyclosporine A (Caro \& Cederbaum, 2004). Similarly, cultured hepatocytes exposed in vitro to ethanol undergo apoptotic changes in association with the formation of ROS and MTP (Adachi \& Ishii, 2002). In both hepatocytes and HepG2 cells ethanol-induced apoptosis is prevented by antioxidants and by the over-expression of the anti-apoptotic protein Bcl-2 (Adachi \& Ishii, 2002; Caro \& Cederbaum, 2004). Thus, oxidative mitochondrial damage can be regarded as one of the mechanisms responsible for the hepatocyte apoptosis associated with advanced ALD (Natori et al. 2001; Ziol et al. 2001). Nonetheless, even when ethanol-induced mitochondrial damage is not sufficiently extensive to be the primary cause of cell death, the impairment of ATP production might be harmful to the liver by enhancing its susceptibility to alcohol-induced centrilobular hypoxia (French et al. 1984).

\section{Oxidative stress in the modulation of hepatic inflammatory reactions induced by alcohol}

One important contribution to the understanding of the pathogenesis of human ALD has originated from studies in the late Ron Thurman's laboratory concerning the role played by inflammatory responses in the mechanisms of alcohol hepatotoxicity (Thurman, 1998). The current view is that ethanol ingestion increases the translocation of gutderived endotoxins to the portal circulation where they stimulate intrahepatic Kupffer cells by interaction with the surface receptor CD14 (Rao et al. 2004). Activated Kupffer cells are then responsible for the synthesis and release of proinflammatory cytokines, particularly TNF- $\alpha$, eicosanoids, ROS and NO (Hines \& Wheeler, 2004). In accordance with this interpretation plasma TNF- $\alpha$ concentrations are increased in patients with ALD and the values correlate with disease severity and mortality (Felver et al. 1990). Moreover, experiments in rats receiving ethanol enterally (Thurman, 1998) have shown that the administration of antibiotics to reduce endotoxaemia or the inactivation of Kupffer cells with $\mathrm{GdCl}_{3}$ prevent liver injury. CD14-knock-out or CD14-coupled Tool-like receptor 4-knock-out mice, which produce less TNF- $\alpha$, are also resistant to alcohol toxicity (Uesugi et al. 2001; Yin et al. 2001). Oxidative stress probably contributes to this proinflammatory action of alcohol, as lipid peroxidation is associated with a marked up-regulation of TNF- $\alpha$ and cyclooxygenase-2 mRNA expression (Nanji et al. 1997), while blocking CYP2E1 induction with chlormethiazole down regulates ethanol-stimulated expression of TNF- $\alpha$ and IL-1 $\beta$ mRNA in the liver of alcohol-fed rats (Fang et al. 1998).

TNF- $\alpha$ is implicated as being an important cause of alcohol hepatotoxicity by the observation that rats receiving anti-TNF- $\alpha$ antibodies as well as TNF receptor 1-knock-out mice are protected against the liver damage induced by enteral administration of alcohol (Hines \& Wheeler, 2004). It is now well established that interaction between TNF- $\alpha$ and TNF receptor 1 induces cell apoptosis by activating several signal pathways that promote caspase activation, ceramide release, MPT and the stimulation of Jun-N-terminal kinase and p38 mitogen-activated kinase (Wajant et al. 2003). However, hepatocytes, like many other cells, are resistant to the pro-apoptotic action of TNF- $\alpha$ because of the concomitant induction of antiapoptotic signals involving both NF- $\kappa \mathrm{B}$-dependent gene transcription and phosphatidylinositol-3-kinase/protein kinase B activation (Wajant et al. 2003). As Hoek \& Pastorino (2004) point out, the way in which ethanol affects the balance between the pro- and anti-apoptotic signals triggered by TNF- $\alpha$ is different, with oxidative stress playing a role in causing the imbalance. Indeed, in HepG2 cells over-expressing CYP2E1 the sensitivity to TNF- $\alpha$ is abolished by the antioxidant ebselen, while in hepatocytes obtained from rats chronically fed ethanol selective depletion of mtGSH is associated with increased susceptibility to the cytotoxic effects of TNF- $\alpha$ (Hoek \& Pastorino, 2004; Fernandez-Checa \& Kaplowitz, 2005). At present, the mechanisms by which ethanol-induced oxidative stress enhances TNF- $\alpha$ toxicity are not fully understood. However, likely targets might be represented by an increased susceptibility of mitochondria to TNF- $\alpha$-induced MPT, as well as the enhanced activation of apoptosis signalling kinase- 1 as a result of the oxidation of its binding protein thioredoxin (Hoek \& Pastorino, 2004). Furthermore, it cannot be excluded that oxidative stress might contribute to ethanol-mediated down-regulation of the anti-apoptotic signals involving phosphatidylinositol-3-kinase/protein kinase B (Shulga et al. 2005). These observations suggest that the interplay between oxidative stress and TNF- $\alpha$ might represent an important cause of the extensive hepatocyte apoptosis that characterizes alcohol-related hepatitis (Natori et al. 2001).

\section{Free radical mechanisms in immune reactions associated with alcoholic liver disease}

Although chronic ethanol exposure increases the Kupffer cell response to endotoxins (McClain et al. 2004) and renders hepatocytes susceptible to TNF- $\alpha$ toxicity (Hoek \& Pastorino, 2004), Kupffer cell activation by endotoxins might not be the only factor responsible for maintaining the chronic inflammatory response in the liver, since continuous exposure to endotoxins promotes tolerance (Ziegler-Heitbrock, 1995), while chronic administration of ethanol in combination with endotoxins fails to increase alcohol hepatoxicity (Jarvelainen et al. 1999). Moreover, rats enterally fed alcohol show liver injury, inflammation and increased TNF- $\alpha$ mRNA expression, even in the absence of appreciable elevations in plasma endotoxins (Ronis et al. 2004).

The immune system is known to have a key role in regulating the inflammatory processes associated with chronic liver diseases (Kita et al. 2001). Early studies (Neuberger et al. 1984; Izumi et al. 1985) have shown the 
presence of circulating antibodies targetting alcohol-altered hepatocytes in patients with ALD. Furthermore, histological examination reveals that liver infiltrates characteristic of alcoholic hepatitis contain both CD8+ and CD4+ T lymphocytes, and their presence correlates with the extension of piecemeal necrosis, intralobular inflammation and regenerating nodules (Chedid et al. 1993). Liver-associated lymphocytes isolated from alcohol-consuming rats have an increased capacity to secrete proinflammatory cytokines (Batey et al. 2002), which suggests that they may contribute to the orchestration of inflammation during the evolution of ALD. Moreover, alcohol consumption increases the activity of natural killer T-cells present in the liver, which may be a causative factor in hepatocyte apoptosis by both TNF- $\alpha$ - and FAS-mediated mechanisms (Minagawa et al. 2004). Further evidence for a role of the immune response in favouring the progression of liver damage towards fibrosis has been provided by a recent report (Safadi et al. 2004) that lymphocyte destruction by sublethal irradiation reduces liver fibrosis in mice treated with $\mathrm{CCl}_{4}$ or thioacetamide, while the transfer of CD8+ lymphocytes from $\mathrm{CCl}_{4}$-treated mice to immuno-deficient SCID mice leads to the fibrogenic activation of hepatic stellate cells (HSC).

The first indication of the possible contribution of oxidative stress in promoting immune reactions in ALD was the observation that antibodies specifically recognizing HER-derived epitopes are detectable in both rats chronically fed ethanol (Albano et al. 1996) and patients with ALD (Clot et al. 1995). Subsequent studies (Mottaran et al. 2002) have shown that elevated titres of circulating IgG towards epitopes derived from the modification of proteins by lipid peroxidation products (MDA, 4-hydroxynonenal and oxidized arachidonic acid) are also present in a large percentage $(55-70)$ of patients with biopsy-proven alcoholic hepatitis and/or cirrhosis, but only in a few (8-13\%) subjects with fatty liver only, irrespective of the magnitude and the duration of alcohol intake. In addition, the combined reaction of MDA and acetaldehyde with the $\varepsilon-\mathrm{NH}_{2}$ group of protein lysine residues generates condensation products, termed MDA-acetaldehyde adducts, that are also antigenic (Thiele et al. 2004) and stimulate immune reactions in advanced ALD (Rolla et al. 2000). The presence of MDA-acetaldehyde adducts could also favour autoimmune processes during the development of alcohol-related liver injury, as mice immunized with MDA-acetaldehyde adduct-containing proteins produce antibodies that recognize not only the MDA-acetaldehyde adduct epitopes but also the carrier proteins (Thiele et al. 2004).

The reasons why alcohol-induced oxidative damage promotes the formation of such a variety of antibodies are still unclear. In order to initiate an antibody response, peptide antigens should be presented by professional antigen-presenting cells to $\mathrm{CD} 4+\mathrm{T}$ lymphocytes in conjunction with molecules of the class II MHC and accessory signals. In the liver professional antigen-presenting cells are represented by hepatic dendritic cells, Kupffer cells and sinusoidal endothelial cells. However, exposure to proinflammatory cytokines induces the expression of both class II MHC and co-stimulatory B7.1 (CD80) molecules in hepatocytes that can then function as antigen-presenting cells to CD4+ T lymphocytes (Herkel et al. 2003). Thus, in the course of ALD the modification of protein by HER or lipid peroxidation products within the hepatocytes might directly trigger the activation of $\mathrm{CD} 4+\mathrm{T}$-cells infiltrating the liver and promote antibody production by the T-helper 2 immune response. It is noteworthy that in about $35 \%$ of patients with advanced ALD (but only $9 \%$ of heavy drinkers without major hepatic damage) the presence of antibodies towards MDA-derived antigens is accompanied by a proliferative response of $\mathrm{CD} 4+\mathrm{T}$ lymphocytes to the same antigens, indicating the involvement of free radical mechanisms in promoting both the humoral and cellular immune reactions associated with ALD (Stewart et al. 2004b)

In addition to developing antibodies directed against a variety of allo-antigens, patients with ALD can often show signs of autoimmune reactions (for review, see McFarlane, 2000). In this context, it has been observed that about $40 \%$ of patients with advanced ALD have circulating IgG directed against CYP2E1 (Vidali et al. 2003). These autoantibodies recognize at least two distinct conformational epitopes present in the C-terminal portion of the CYP2E1 molecule (Vidali et al. 2004). One of the mechanisms proposed to explain the formation of anti-CYP autoantibodies postulates that the binding of reactive drug metabolites to CYP promotes a humoral immune response against the modified protein and concomitantly favours the activation of normally-quiescent auto-reactive lymphocytes, which leads to the production of antibodies to the native CYP molecules (Van Pelt et al. 1995). Patients with ALD who have anti-HER antibodies have a 4-fold increased risk of developing anti-CYP2E1 auto-reactivity as compared with patients without anti-HER IgG, which indicates that CYP2E1 alkylation by HER is critical for the development of anti-CYP2E1 auto-reactivity in ALD (Vidali et al. 2003). Nonetheless, genetic factors are also involved. In particular, it has been observed that the presence of an $\mathrm{A} \rightarrow \mathrm{G}$ base exchange at position 49 in exon 1 of the gene encoding cytotoxic $\mathrm{T}$ lymphocyte-associated antigen-4 (a membrane receptor that down regulates T-cell-mediated immune responses; Egen et al. 2002) increases by $3 \cdot 8$-fold the risk of developing anti-CYP2E1 $\mathrm{IgG}$ without influencing the formation of antibodies towards HER antigens. Interestingly, the risk of developing anti-CYP2E1 auto-reactivity in patients with ALD who have both anti-HER IgG and the mutant cytotoxic $\mathrm{T}$ lymphocyte-associated antigen-4 G allele is 23 -fold higher than that in subjects negative for both these factors (Vidali et al. 2003). Thus, antigenic stimulation by HERmodified CYP2E1 in combination with impaired control of T-cell proliferation as a result of the cytotoxic $\mathrm{T}$ lymphocyte-associated antigen-4 mutation promotes the development of anti-CYP2E1 auto-antibodies. The contribution of both allo- and auto-reactivity involving CYP2E1 to hepatic injury by alcohol is suggested by the observation that anti-HER IgG recognize HER-CYP2E1 adducts on the outer layer of the plasma membranes of ethanol-treated hepatocytes where they activate antibodydependent cell-mediated cytotoxicity (Clot et al. 1997). Interestingly, an epidemiological prospective survey has associated the presence of antibodies towards 
alcohol-modified hepatocytes with an increased risk of developing alcoholic liver cirrhosis (Takase et al. 1993). Antibody-dependent cytotoxicity would also result from the recognition of plasma membrane CYP2E1 by antiCYP2E1 auto-antibodies. Indeed, preliminary data (Stewart et al. 2004a) indicates that high titres of antiCYP2E1 auto-antibodies correlate with the extension of lymphocyte infiltration and the number of apoptotic hepatocytes.

Anti-phospholipid antibodies are among the autoantibodies most frequently associated with ALD, being detectable in $\leq 80 \%$ of patients with alcoholic hepatitis or cirrhosis (McFarlane, 2000). It has been observed (Rolla et al. 2000) that oxidative stress markers are increased in patients with ALD who have anti-phospholipid antibodies and that these antibodies are largely directed towards oxidized phospholipids. The current view (Savill et al. 2002) is that impaired macrophage clearance of apoptotic corpses is one of the causes of the development of anti-phospholipid auto-reactivity. Indeed, the production of anti-phospholipid antibodies can be induced by the immunization of mice with syngenic apoptotic lymphocytes, but not with viable cells (Levine et al. 1999). The possibility that defective clearance of apoptotic hepatocytes might contribute to the development of anti-phospholipid reactions during the progression of ALD is suggested by the observations that: (1) chronic alcohol consumption affects the capacity of hepatocytes to scavenge apoptotic bodies through interaction with the asialoglycoprotein receptors (McVicker et al. 2002); (2) anti-phospholipid antibodies from patients with ALD recognize apoptotic, but not living, hepatic cells by specifically targetting oxidized phosphatidylserine on the outer layer of apoptotic bodies (Vay et al. 2006). This specificity is consistent with recent reports (Kagan et al. 2003) showing that phosphatidylserine is oxidized during apoptosis by interaction with cytochrome $\mathrm{c}$ and is then exposed on the outer layer of cell plasma membranes. The actual relevance of the association between severe ALD and anti-phospholipid immune reactivity is still poorly understood (McFarlane, 2000). According to recent evidence (Kagan et al. 2003; Gregory \& Devitt, 2004), the phagocytosis of apoptotic bodies is important in the termination of inflammation, and the presence of phosphatidylserine, or more likely oxidized phosphatidylserine (Kagan et al. 2003), on the surface of apoptotic cells represents a key signal for stimulating macrophages to secrete the anti-inflammatory cytokine transforming growth factor $\beta 1$ and IL-10 (Gregory \& Devitt, 2004). It is proposed that the masking of these recognition sites by IgG targetting oxidized phosphatidylserine (Vay et al. 2006) would not only interfere with such an anti-inflammatory response, but might also favour the proinflammatory activation of phagocytes that recognize the apoptotic bodies through the IgG Fc receptors. Thus, in the presence of anti-phospholipid antibodies ethanol-induced hepatocyte apoptosis might represent a fuel for the perpetuation of inflammation. Indeed, in human and experimental alcoholic hepatitis apoptotic hepatocytes co-localize with neutrophil infiltration, which correlates with the severity of tissue damage (Jaeschke, 2002). Moreover, Gores' group (Canbay et al. 2003) has shown that the engulfment of Kuppfer cells by apoptotic bodies stimulates the expression of TNF- $\alpha$ and Fas ligand.

Together these observations indicate that alcoholinduced oxidative stress triggers the production of a variety of allo-antibodies and, in combination with genetic predisposition, can favour the breaking of self-tolerance in the liver. Oxidative stress-mediated immune responses might represent one of the mechanisms by which alcohol abuse promotes and maintains inflammatory processes during the evolution of ALD. In support of this possibility Ronis et al. (2005) have reported that in an endotoxin-free enteral alcohol model lipid peroxidation directly correlates with both TNF- $\alpha$ mRNA expression and the extent of inflammatory infiltrates, while supplementation with $\mathrm{N}$-acetylcysteine reduces hepatic inflammation along with the immune response triggered by HER and lipid peroxidation products.

\section{Oxidative mechanisms in the onset of alcohol-induced liver fibrosis}

Liver fibrosis and cirrhosis represent the terminal stage of ALD and are one of the main causes of death among patients with alcohol abuse. Research performed in recent years (Friedman, 2003; Battaler \& Brenner, 2005) has given new insights into the mechanisms responsible for liver fibrosis, showing that HSC (perisinusoidal fat-storing cells or Ito cells) under the influence of transforming growth factor $\beta 1$, platelet-derived growth factor and macrophage-stimulating factor 1 transform into myofibroblastlike cells that produce collagen and extracellular matrix components. Oxidative stress contributes to HSC activation by different means. Intracellular redox changes in Kupffer cells activate NF- $\kappa \mathrm{B}$ and activator protein-1, which trigger the transcriptional up-regulation of the genes encoding for fibrogenetic cytokines that stimulate HSC (Parola \& Robino, 2001). Moreover, in vitro studies (Caro \& Cederbaum, 2004) show that oxidative stress directly promotes collagen synthesis in HSC that over-express the CYP2E1 gene. This effect is probably mediated by aldehydic products of lipid peroxidation, as concentrations of 4-hydroxynonenal comparable with those detected in vivo act as a potent profibrogenic stimulus for activated human HSC, up regulating both procollagen I and tissue inhibitor of metalloproteinase-1 expression (Parola \& Robino, 2001; Zamara et al 2004). In addition, interaction between MDAmodified proteins and the CD36 scavenger receptors on HSC membranes is also capable of stimulating the synthesis of fibronectin and collagen (Schneiderhan et al. 2001). Despite the difficulty of reproducing alcoholic fibrosis in animal models of ALD, several studies have shown that detection of MDA and 4-hydroxynonenal in the liver precedes the appearance of the initial signs of fibrosis (Kamimura et al. 1992; Kamimura \& Tsukamoto, 1995; Niemelä et al. 1995) and is associated with transforming growth factor $\beta 1$ production by Kupffer cells (Kamimura $\&$ Tsukamoto, 1995). Ethanol-stimulated transforming growth factor $\beta 1$ synthesis is particularly evident in the perivenous regions and is abolished by CYP2E1 inhibition with chlormethiazole (Fang et al. 1998). Using the enteral alcohol model Tsukamoto et al. (1995) have also observed 
that ethanol-induced liver fibrosis is exacerbated by the combined administration of carbonyl Fe. This effect is closely associated with the promotion of MDA and 4-hydroxynonenal formation as well as with an increase in transforming growth factor $\beta 1$ and procollagen- $\alpha-1$ mRNA expression in both the whole liver and freshlyisolated HSC (Tsukamoto et al. 1995). In human subjects elevated titres of antibodies towards lipid peroxidation adducts or oxidized phospholipids are prevalent in heavy drinkers with fibrosis or cirrhosis, irrespective of the magnitude and the duration of alcohol intake (Rolla et al. 2000; Mottaran et al. 2002). These antibodies are also higher in patients with severe cirrhosis (Child's (Child \& Turcotte, 1964) grade B and C) as compared with those with the milder disease (Child's grade A), suggesting the possibility that an immune response involving lipid peroxidation antigens might also have a role in the progression of alcohol-induced liver damage to fibrosis. Furthermore, the presence of high titres of anti-MDA antibodies in patients with non-alcoholic fatty liver disease increases by 3 -fold the risk of developing advanced fibrosis or cirrhosis as compared with patients whose antibody titres are within the control range (Albano et al. 2005). Although these results are far from being conclusive, they strongly suggest the possible contribution of ethanolinduced oxidative stress to the progression of ALD to liver fibrosis.

\section{Conclusions}

In conclusion, experimental and clinical studies not only demonstrate the association between free radical-mediated oxidative damage and alcohol hepatotoxicity, but also begin to unravel the cellular mechanisms involved. Growing evidence indicates that oxidative mitochondrial damage directly causes hepatocyte death and favours alcohol-induced sensitization to the pro-apoptotic action of TNF- $\alpha$. Moreover, by regulating gene expression oxidative events probably contribute to the development of hepatic fibrosis. Immunological reactions against antigens originating from HER or lipid oxidation products can be regarded as an additional mechanism in the pathogenesis of alcoholic liver injury, as they might contribute to the perpetuation of chronic inflammatory processes. Together these observations provide a rationale for the possible clinical application of antioxidant compounds to reduce the progression of ALD.

\section{References}

Adachi M, Higuchi H, Miura S, Azuma T, Inokuchi S, Saito H, Kato S \& Ishii H (2004) Bax interacts with voltage-dependent anion channel and mediates ethanol-induced apoptosis in rat hepatocytes. American Journal of Physiology 287, G695G705.

Adachi M \& Ishii H (2002) Role of mitochondria in alcoholic liver injury. Free Radical Biology and Medicine 32, 487-491.

Albano E (2002) Free radicals and alcohol-induced liver injury. In Ethanol and the Liver, pp. 153-190 [CDIN Sherman, VR Preedy and RR Watson, editors]. London: Taylor and Francis.
Albano E, Clot P, Morimoto M, Tomasi A, Ingelman-Sundberg M \& French SW (1996) Role of cytochrome P4502E1-dependent formation of hydroxyethyl free radicals in the development of liver damage in rats intragastrically fed with ethanol. Hepatology 23, 155-163.

Albano E, Mottaran E, Vidali M, Vidali M, Reale E, Saksena S, Occhino D, Burt AD \& Day CP (2005) Immune response toward lipid peroxidation products as a predictor of the progression of non-alcoholic fatty liver disease (NAFLD) to advanced fibrosis. Gut 54, 987-993.

Albano E, Parola M, Comoglio A, \& Dianzani MU (1993) Evidence for the covalent binding of hydroxyethyl radicals to rat liver microsomal proteins. Alcohol and Alcoholism 28, 453459.

Albano E, Tomasi A \& Ingelman-Sundberg M (1994) Spin trapping of alcohol-derived radicals in microsomes and reconstituted systems by electron spin resonance. Methods in Enzymology 233, 117-127.

Aleynik SI, Leo MA, Aleynik MK \& Lieber CS (1998) Increased circulating products of lipid peroxidation in patients with alcoholic liver disease. Alcoholism, Clinical and Experimental Research 22, 192-196.

Arteel GE (2003) Oxidant and antioxidant in alcohol-induced liver disease. Gastroenterology 124, 778-790.

Bailey SM \& Cunningham CC (2002) Contribution of mitochondria to oxidative stress associated with alcohol liver disease. Free Radical Biology and Medicine 32, 11-16.

Bardag-Gorce F, Yuan QX, Li J, French BA, Fang C, IngelmanSundberg M \& French SW (2000) The effect of ethanolinduced cytochrome P4502E1 on the inhibition of proteasome activity by alcohol. Biochemical and Biophysical Research Communications 279, 23-29.

Batey RG, Cao Q \& Gould B (2002) Lymphocyte-mediated liver injury in alcohol-related hepatitis. Alcohol 27, 37-41.

Battaler R \& Brenner DA (2005) Liver fibrosis. Journal of Clinical Investigation 115, 209-218.

Bautista AP (2002) Neutrophilic infiltration in alcoholic hepatitis. Alcohol 27, 17-21.

Bautista AP \& Spitzer JJ (1994) Inhibition of nitric oxide formation in vivo enhances superoxide release by the perfused liver. American Journal of Physiology 266, G783-G788.

Bautista AP \& Spitzer JJ (1996) Postbinge effects of acute alcohol intoxication on hepatic free radical formation. Alcoholism, Clinical and Experimental Research 20, 502-509.

Beckman JS \& Koppenol WH (1996) Nitric oxide, superoxide and peroxynitrite: the good, the bad and the ugly. American Journal of Physiology 271, C1424-C1437.

Bell H, Bjørneboe A, Eidsvoll B, Norum KR, Raknerud N, Try K, Thomansen Y \& Drevon CA (1992) Reduced concentration of hepatic $\alpha$-tocopherol in patients with alcoholic liver cirrhosis. Alcohol and Alcoholism 27, 39-46.

Bernardi P, Petronilli V, Di Lisa F \& Forte M (2001) A mitochondrial perspective on cell death. Trends in Biochemical Sciences 26, 112-117.

Bradford $\mathrm{BU}$, Kona $\mathrm{H}$, Isayama $\mathrm{F}$, Kosyk $\mathrm{O}$, Wheeler $\mathrm{MD}$, Akiyama TE, Bleye L, Krausz KW, Gonzalez FJ, Koop DR \& Rusyn I (2005) Cytochrome P450 CYP2E1, but not nicotinamide adenine dinucleotide phosphate oxidase is required for ethanol-induced oxidative DNA damage in rodent liver. Hepatology 41, 336-344.

Brind AM, Hurlstone A, Edrisinghe D, Gilmore I, Fisher N, Pirmohamed M \& Fryer AA (2004) The role of polymorphisms of glutathione S-transferases GSTM1, M3, P1, T1 and A1 in susceptibility to alcoholic liver disease. Alcohol and Alcoholism 39, 478-483.

Canbay A, Feldstein AE, Higuchi H, Werneburg N, Grambihler A, Bronk SF \& Gores GJ (2003) Kupffer cell engulfment of 
apoptotic bodies stimulates death ligand and cytokine expression. Hepatology 38, 1188-1198.

Caro AA \& Cederbaum AI (2004) Oxidative stress, toxicology and pharmacology of CYP2E1. Annual Review of Pharmacology and Toxicology 44, 27-42.

Chamulitrat W \& Spitzer JJ (1996) Nitric oxide and liver injury in alcohol-fed rats after lipipolysaccaride administration. Alcoholism, Clinical and Experimental Research 20, 10651070.

Chedid A, Mendenhall CL, Moritz TE, French SA, Chen TS, Morgan TR et al. (1993) Cell-mediated hepatic injury in alcoholic liver disease. Veterans Affairs Cooperative Study Group 275. Gastroenterology 105, 254-266.

Child CG \& Turcotte JG (1964) Surgery and portal hypertension. In The Liver and Portal Hypertension, pp. 50-64 [CG Child, editor]. Philadelphia, PA: Saunders.

Clot P, Albano E, Elliasson E, Tabone M, Aricò S, Israel Y, Moncada Y \& Ingelman-Sundberg M (1996) Cytochrome P4502E1 hydroxyethyl radical adducts as the major antigenic determinant for autoantibody formation among alcoholics. Gastroenterology 111, 206-216.

Clot P, Bellomo G, Tabone M, Aricò S \& Albano E (1995) Detection of antibodies against proteins modified by hydroxyethyl free radicals in patients with alcoholic cirrhosis. Gastroenterology 108, 201-207.

Clot P, Parola M, Bellomo G, Dianzani U, Carini R, Tabone M, Aricò S, Ingelman-Sundberg M \& Albano E (1997) Plasma membrane hydroxyethyl radical adducts cause antibodydependent cytotoxicity in rat hepatocytes exposed to alcohol. Gastroenterology 113, 265-276.

Clot P, Tabone M, Aricò S \& Albano E (1994) Monitoring oxidative damage in patients with liver cirrhosis and different daily alcohol intake. Gut 35, 1637-1643.

Coll O, Colell A, Garcia-Ruiz C, Kaplowitz N \& FernandezCheca JC (2003) Sensitivity of the 2-oxoglutarate carrier to alcohol intake contributes to mitochondrial glutathione depletion. Hepatology 38, 692-702.

Dandona P, Aljada A \& Bandyopadhyay A (2004) Inflammation: the link between insulin resistance, obesity and diabetes. Trends in Immunology 25, 4-7.

Di Luzio NR (1963) Prevention of acute ethanol-induced fatty liver by antioxidants. Physiologist 6, 169-173.

Dupont I, Lucas D, Clot P, Ménez C \& Albano E (1998) Cytochrome P4502E1 inducibility and hydroxyethyl radical formation among alcoholics. Journal of Hepatology 28, 564-571.

Egen JG, Kuhns MS \& Allison JP (2002) CTLA-4: new insights into its biological function and use in tumor immunotherapy. Nature Immunology 3, 611-618.

Fang C, Lindros KO, Badger TM, Ronis JJ \& Ingelman-Sundberg M (1998) Zonated expression of cytokines in rat liver: effect of chronic ethanol and cytochrome P4502E1 inhibitor, chlormethiazole. Hepatology 27, 1304-1310.

Felver ME, Mezey E, McGuire M, Mitchell MC, Herlong HF, Veech GA \& Veech RL (1990) Plasma tumor necrosis factor alpha predicts decreased long-term survival in severe alcoholic hepatitis. Alcohol, Clinical and Experimental Research 14, 255-259.

Fernandez-Checa JC, Garcia-Ruiz C, Ookhtens M \& Kaplowitz N (1991) Impaired uptake of glutathione by hepatic mitochondria from ethanol fed rats. Journal of Clinical Investigation 87, 397-405.

Fernandez-Checa JC \& Kaplowitz N (2005) Hepatic mitochondrial glutathione: transport and role in disease and toxicity. Toxicology and Applied Pharmacology 204, 263-273.

French SW, Benson NC \& Sun PS (1984) Centrilobular liver necrosis induced by hypoxia in chronic ethanol-fed rats. Hepatology 4, 912-917.
Friedman SL (2003) Liver fibrosis: from bench to bedside. Journal of Hepatology 38, Suppl. 1, S38-S53.

Fromenty B, Grimbert S, Mansouri A, Beaugrand M, Erlinger S, Röting A \& Pessayre D (1995) Hepatic mitochondrial DNA deletion in alcoholics: association with microvesicular steatosis. Gastroenterology 108, 193-200.

Fromenty B \& Pessayre D (1995) Inhibition of mitochondrial beta-oxidation as a mechanism of hepatotoxicity. Pharmacology and Therapeutics 67, 101-154.

Garcia-Ruiz C, Colell A, Paris R \& Fernandez-Checa JC (2000) Direct interaction of GD3 ganglioside with mitochondria generates reactive oxygen species followed by mitochondrial permeability transition, cytochrome $\mathrm{c}$ release and caspase activation. FASEB Journal 14, 847-850.

Garcia-Ruiz C, Morales A, Ballesta A, Rhodes J, Kaplowitz N \& Fernandez-Checa JC (1994) Effect of chronic ethanol feeding on glutathione and functional integrity of mitochondria in periportal and perivenous rat hepatocytes. Journal of Clinical Investigation 94, 193-201.

Girre C, Lucas D, Hispard E, Ménez C, Dally S, Ménez JF (1994) Assessment of cytochrome P4502E1 induction in alcoholic patients by chlozoxazone pharmacokinetics. Biochemical Pharmacology 47, 1503-1508.

Gouillon Z, Lucas D, Li J, Hagbjork AL, French BA, Fu P, Fang C, Ingelman-Sundberg M, Donohue TM \& French SW (2000) Inhibition of ethanol-induced liver disease in the intragastric feeding rat model by chlormethiazole. Proceedings of the Society for Experimental Biology and Medicine 224, 302-308.

Green DR \& Kroemer G (2004) The pathophysiology of mitochondrial cell death. Science 305, 626-629.

Gregory CD \& Devitt A (2004) The macrophage and the apoptotic cell: an innate immune interaction viewed simplistically? Immunology 113, 1-14.

Herkel J, Jagemann B, Weigard C, Garcia Lazaro JF, Lueth S, Kanzler S, Blessing M, Schmitt E \& Lohse AW (2003) MCH class II-expressing hepatocytes function as antigen presenting cells and activate specific CD4 T lymphocytes. Hepatology 37, $1079-1085$

Hines IN \& Wheeler MD (2004) Recent advances in alcoholic liver disease III. Role of the innate immune response in alcoholic hepatitis. American Journal of Physiology 287, G310 G314.

Hirano T, Kaplowitz N, Kamimura T, Tsukamoto H \& Fernandez-Checa JC (1992) Hepatic mitochondrial GSH depletion and progression of experimental alcoholic liver disease in rats. Hepatology 16, 1423-1428.

Hoek JB, Cahill A \& Pastorino JG (2002) Alcohol and mitochondria: a dysfunctional relationship. Gastroenterology $\mathbf{1 2 2}$, 2049-2063.

Hoek JB \& Pastorino JG (2004) Cellular signalling mechanisms in alcoholic liver damage. Seminars in Liver Diseases 24, 257 272.

Iimuro Y, Bradford BU, Yamashina S, Rusyn I, Nakagami M, Enomoto N, Kono H, Frey W, Forman D, Brenner D \& Thurman RG (2000) The glutathione precursor L-2-oxothiazolidine4-carboxylic acid protects against liver injury due to chronic enteral ethanol exposure in the rat. Hepatology 31, 391-398.

Ioannou GN, Dominitz JA, Weiss NS, Haegerty PJ \& Wowdley KV (2004) The effect of alcohol consumption on the prevalence of iron overload, iron deficiency and ion deficiency anemia. Gastroenterology 126, 1293-1301.

Irving MG, Halliday JW \& Powell LW (1988) Association between alcoholism and increased hepatic iron store. Alcoholism, Clinical and Experimental Research 12, 7-12.

Ishak KG, Zimmerman HJ \& Ray MB (1991) Alcoholic liver disease: pathology, pathogenetic and clinical aspects. Alcoholism, Clinical and Experimental Research 15, 45-66. 
Izumi N, Sato C, Hamusura Y \& Takeuchi J (1985) Serum antibodies against alcohol-treated hepatocytes in patients with alcoholic liver diseases. Clinical and Experimental Immunology 61, 585-592.

Jaeschke H (2002) Neutrophil-mediated tissue injury in alcoholic hepatitis. Alcohol 27, 23-27.

Jarvelainen HA, Fang C, Ingelman-Sundberg M \& Lindros KO (1999) Effect of chronic coadministration of endotoxin and ethanol on rat liver pathology and proinflammatory and antiinflammatory cytokines. Hepatology 29, 1503-1510.

Kagan VE, Borisenko GG, Serinkan BF, Tyurina YY, Tyurin VA, Jiang J, Liu SX, Shvedova AA, Fabisial JP, Uthsaisang W \& Fadeel B (2003) Appetizing rancidity of apoptotic cells for macrophages: oxidation, externalization and recognition of phosphatidylserine. American Journal of Physiology 285, L1-L17.

Kamimura S, Gall K, Britton SR, Bacon BR, Triadafilopulos G \& Tsukamoto H (1992) Increased 4-hydroxynonenal levels in experimental alcoholic liver disease: Association of lipid peroxidation with liver fibrogenesis. Hepatology 16, 448-453.

Kamimura S \& Tsukamoto H (1995) Cytokine gene expression by Kupffer cells in experimental alcoholic liver disease. Hepatology 21, 1304-1309.

Kawase T, Kato S \& Lieber CS (1989) Lipid peroxidation and antioxidant defense systems in rat liver after chronic ethanol feeding. Hepatology 10, 815-821.

Kessova IG, Ho YS, Thung S \& Cederbaum AI (2003) Alcoholinduced liver injury in mice lacking $\mathrm{Cu}, \mathrm{Zn}$-superoxide dismutase. Hepatology 38, 1136-1145.

Kita H, Mackay IR, Van de Water J, \& Gershwin EM (2001) The lymphoid liver: considerations on pathways to autoimmune injury. Gastroenterology 120, 1485-1501.

Knecht KT, Adachi Y, Bradfort BU, Iimuro Y, Kadiiska M, QunHui X \& Thurman RG (1995) Free radical adducts in the bile of ras treated chronically with intragastric alcohol: inhibition by destruction of Kupffer cells. Molecular Pharmacology 47, $1028-1034$.

Kono H, Arteel GE, Rusyn I, Sies H \& Thurman RG (2001a) Ebselen prevents early alcohol-induced liver injury in rats. Free Radical Biology and Medicine 30, 403-411.

Kono H, Bradford BU, Yin M, Sulik KK, Koop DR, Peters JM et al. (1999) CYP2E1 is not involved in early alcohol-induced liver injury. American Journal of Physiology 277, G1259G1267.

Kono H, Rusyn I, Yin M, Gabele E, Yamashina S, Dikalova A et al. (2000) NADPH oxidase-derived free radicals are key oxidants in alcohol-induced liver disease. Journal of Clinical Investigation 106, 867-872.

Kono H, Uesugi T, Froh M, Rusyn I, Bradford BU \& Thurman RG (2001b) ICAM-1 is involved in the mechanism of alcoholinduced liver injury: studies with knockout mice. American Journal of Physiology 280, G1289-G1295.

Levine JS, Koh JS, Subang R \& Rauch J (1999) Apoptotic cells as immunogen and antigen in the anti-phospholipid syndrome. Experimental and Molecular Pathology 66, 82-98.

Li J \& Billiar TR (1999) Nitric Oxide. IV. Determinants of nitric oxide protection and toxicity in liver. American Journal of Physiology 276, G1069-G1073.

Liangpunsakul S, Kolwankar D, Pinto A, Gorski CJ, Hall SD \& Chalasani N (2005) Activity of CYP2E1 and CYP3A enzymes in adults with moderate alcohol consumption: a comparison with nonalcoholics. Hepatology 41, 1144-1150.

McClain CJ, Song Z, Barve SS, Hill DB \& Deaciuc I (2004) Recent advances in alcoholic liver disease IV. Dysregulated cytokine metabolism in alcoholic liver disease. American Journal of Physiology 287, G497-G502.
McFarlane IG (2000) Autoantibodies in alcoholic liver disease. Addiction Research 5, 141-151.

McKim SE, Gabele E, Isayama F, Lambert JC, Tucker LM, Wheeler MD, Connor HD, Mason RP, Doll MA, Hein DW \& Arteel GE (2003) Inducible nitric oxide synthase is required in alcohol-induced liver injury: studies with knockout mice. Gastroenterology 125, 1834-1844.

McVicker BL, Tuma DJ, Kubik JA, Hindemith AM, Baldwin CR $\&$ Casey CA (2002) The effect of ethanol on asialoglycoprotein receptor-mediated phagocytosis of apoptotic cells by rat hepatocytes. Hepatology 36, 1478-1487.

Mansouri A, Fromenty B, Berson A, Robin MA, Grimbert S, Beaugrand M, Erlinger S \& Pessayre D (1997) Multiple hepatic mitochondrial DNA deletions suggest premature oxidative aging in alcoholics. Journal of Hepatology 27, 96-102.

Matsuhashi T, Karbowski M, Liu X, Usukura J, Wozniak M \& Wakabayashi T (1998) Complete suppression of ethanolinduced formation of megamitochondria by 4-hydroxy-2,2,6,6,tetramethyl-piperidine-1-oxyl (4-OH-TEMPO). Free Radical Biology and Medicine 24, 139-147.

Meager EA, Barry OP, Burke A, Lucey MR, Lawson JA, Rokach J \& FitzGerald GA (1999) Alcohol-induced generation of lipid peroxidation products in humans. Journal of Clinical Investigation 104, 805-813.

Mezey E, Potter JJ, Rennie-Tankersley 1, Caballeire J \& Pares A (2004) A randomized placebo controlled trial of vitamin $\mathrm{E}$ for alcoholic hepatitis. Journal of Hepatology 40, 40-46.

Minagawa M, Deng Q, Liu ZX, Tzukamoto H \& Dennert G (2004) Activated natural killer T cells induce liver injury by Fas and tumor necrosis factor- $\alpha$ during alcohol consumption. Gastroenterology 126, 1387-1399.

Moncada C, Torres V, Vargese E, Albano E \& Israel Y (1994) Ethanol-derived immunoreactive species formed by free radical mechanisms. Molecular Pharmacology 46, 786-791.

Morgan K, French SW \& Morgan TR (2002) Production of a cytochrome P450 2E1 transgenic mouse and initial evaluation of alcoholic liver damage. Hepatology 36, 122-134.

Mottaran E, Stewart SF, Rolla R, Vay D, Cipriani V, Moretti MG, Vidali M, Sartori M, Rigamonti C, Day CP \& Albano E (2002) Lipid peroxidation contributes to immune reactions associated with alcoholic liver disease. Free Radical Biology and Medicine 32, 38-48.

Nakao LS \& Augusto O (1998) Nucleic acid alkylation by free radical metabolites of ethanol. Formation of 8-(1-hydroxyethyl)guanine and 8-(2-hydroxyethyl)guanineadducts. Chemical Research in Toxicology 11, 888-894.

Nanji AA \& French SW (1989) Dietary linoleic acid is required for development of experimentally induced alcoholic liver disease. Life Sciences 44, 223-227.

Nanji AA, Greenberg SS, Tahan SR, Fogt F, Loscalzo J, Sadrzadeh SMH, Xie J \& Stamler JS (1995a) Nitric oxide production in experimental alcoholic liver disease in the rat: role in protection from injury. Gastroenterology 109, 899-907.

Nanji AA, Griniuviene B, Sadrzadeh SMH, Levitsky S \& McCully JD (1995b) Effect of dietary fat and ethanol on antioxidant enzyme mRNA induction in rat liver. Journal of Lipid Research 36, 736-744.

Nanji AA, Khwaja S, Tahan SR \& Sadrzadeh HSM (1994a) Plasma levels of a novel noncyclooxygenase-derived prostanoid (8-isoprostane) correlate with severity of liver injury in experimental alcoholic liver disease. Journal of Pharmacology and Experimental Therapeutics 269, 1280-1285.

Nanji AA, Miao L, Thomas P, Rahemtulla T, Khwaja S, Zhao S, Peters D, Tahan SR \& Dannenberg AJ (1997) Enhanced cycloxygenase-2 gene expression in alcoholic liver disease in rats. Gastroenterology 112, 943-951. 
Nanji AA, Sadrzadeh SMH, Yang EK, Fogt F, Maydani M \& Dannenberg AJ (1995b) Dietary saturated fatty acids: A novel treatment for alcoholic liver disease. Gastroenterology 109, 547-554.

Nanji AA, Yang EK, Fogt F, Sadrzadeh SMH \& Dannenberg AJ (1996) Medium chain triglycerides and vitamin E reduce the severity of established experimental alcoholic liver disease. Journal of Pharmacology and Experimental Therapeutics 277, 1694-1700.

Nanji AA, Zhao S, Sadrzadeh SMH, Dannenberg AJ, Tahan SR \& Waxman DJ (1994b) Markedly enhanced cytochrome P4502E1 induction and lipid peroxidation is associated with severe liver injury in fish oil-treated ethanol-fed rats. Alcoholism, Clinical and Experimental Research 18, 1280-1285.

Natori S, Rust C, Stadheim LM, Srinivasan A, Burgart LJ \& Gores GJ (2001) Hepatocyte apoptosis is a pathological feature of human alcoholic hepatitis. Journal of Hepatology 34, 248253.

Neuberger J, Crossley IR, Saunders JB, Davis M, Portmann B, Eddleston ALWF \& Williams R (1984) Antibodies to alcohol altered liver cell determinants in patients with alcoholic liver disease. Gut 25, 300-304.

Neve EP \& Ingelman-Sundberg M (2001) Identification and characterization of a mitochondrial targeting signal in rat cytochrome P450 2E1 (CYP2E1). Journal of Biological Chemistry 276, 11317-11322.

Niemelä O, Parkkila S, Ylä-Herttuala S, Halsted C, Witztum JL, Lanca A \& Israel Y (1994) Covalent protein adducts in the liver as a result of ethanol metabolism and lipid peroxidation. Laboratory Investigation 70, 537-546.

Niemelä O, Parkkila S, Ylä-Herttuala S, Villanueva J, Ruebner B \& Halsted CH (1995) Sequential acetaldehyde production, lipid peroxidation and fibrogenesis in micropigs model of alcoholinduced liver disease. Hepatology 22, 1208-1214.

Nordmann R, Ribière C \& Rouach H (1992) Implication of free radical mechanisms in ethanol induced cellular injury. Free Radical Biology and Medicine 12, 219-240.

Parola M \& Robino G (2001) Oxidative stress-related molecules and liver fibrosis. Journal of Hepatology 35, 297-306.

Polavarapu R, Spitz DR, Sim JE, Follansbee MH, Oberley LW, Rahemtulla A \& Nanji AA (1998) Increased lipid peroxidation and impaired antioxidant enzyme function is associated with pathological liver injury in experimental alcoholic liver disease in rats fed diets high in corn oil and fish oil. Hepatology 27, $1317-1323$

Rao RK, Seth A \& Sheth P (2004) Recent advances in alcoholic liver disease. I. Role of intestinal permeability and endotoxemia in alcoholic liver disease. American Journal of Physiology 286, G881-G884.

Rolla R, Vay D, Mottaran E, Parodi M, Traverso N, Arico S et al. (2000) Detection of circulating antibodies against malondialdehyde-acetaldehyde adducts in patients with alcoholinduced liver disease. Hepatology 31, 878-884.

Ronis MJJ, Butura A, Sampey BP, Prior RL, Korourian S, Albano E, Ingelman-Sundberg M, Petersen DR \& Badger TM (2005) Effects of $\mathrm{N}$-acetyl cysteine on ethanol-induced hepatotoxicity in rats fed via total enteral nutrition. Free Radical Biology and Medicine 36, 616-630.

Ronis MJJ, Hakkak R, Korourian S, Albano E, Yoon S, Ingelman-Sundberg M, Lindros KO \& Badger TM (2004) Alcoholic liver disease in rats fed ethanol as part of oral or intragastric low-carbohydrate diets. Experimental Biology and Medicine 229, 351-360.

Ronis MJJ, Lindros KO \& Ingelman-Sundberg M (1996) The CYP2E family. In Cytochromes P450: Metabolic and Toxicological Aspects, pp. 211-239 [C Ioannides, editor]. Boca Raton, FL: CRC Press.
Rouach H, Fattaccioli V, Gentil M, French SW, Morimoto M \& Nordmann R (1997) Effect of chronic ethanol feeding on lipid peroxidation and protein oxidation in relation to liver pathology. Hepatology 25, 351-355.

Rouault TA (2003) Hepatic iron overload in alcoholic liver disease: why does it occur and what is its role in pathogenesis? Alcohol 30, 103-106.

Sadrzadeh SMH, Hallaway PE \& Nanji AA (1997) The longacting parenteral iron chelator hydroxyethylstarch-desferoxamine fails to protect against alcohol-induced liver injury in rats. Journal of Pharmacology and Experimental Therapeutics 280, 1038-1042.

Sadrzadeh SMH, Meydani M, Khettry U \& Nanji AA (1995) High-dose vitamin E supplementation has no effect on ethanolinduced pathological liver injury. Journal of Pharmacology and Experimental Therapeutics 273, 455-460.

Sadrzadeh SMH \& Nanji AA (1998) The 21-aminosterolid 16desmethyl-tirilazad mesylate prevents necroinflammatory changes in experimental alcoholic liver disease. Journal of Pharmacology and Experimental Therapeutics 284, 406-412.

Sadrzadeh SMH, Nanji AA \& Meydani M (1994a) Effect of chronic ethanol feeding on plasma and liver $\alpha$ - and $\gamma$-tocopherol levels in normal and vitamin E-deficient rats. Biochemical Pharmacology 47, 2005-2010.

Sadrzadeh SMH, Nanji AA \& Prince PL (1994b) The oral iron chelator 1,2-dimethyl-3-hydroxypyrid-4-one reduces hepatic free iron, lipid peroxidation and fat accumulation in chronically ethanol-fed rats. Journal of Pharmacology and Experimental Therapeutics 269, 632-636.

Safadi R, Ohta M, Alvarez CE, Fiel MI, Bansal M, Mehal WZ \& Friedman SL (2004) Immune stimulation of hepatic fibrogenesis by CD8 cells and attenuation by transgenic interleukin-10 from hepatocytes. Gastroenterology 127, 870-882.

Savill J, Dransfield I, Gregory C \& Haslett C (2002) A blast from the past: clearance of apoptotic cells regulates immune responses. Nature Reviews Immunology 2, 965-975.

Schneiderhan W, Schmid-Kotsas A, Zhao J, Grunert A, Nusslaer A, Weidenbach H, Menke A, Schmid RM, Adler G \& Bachem MG (2001) Oxidized low-density lipoproteins bind to the scavenger receptor, CD36, of hepatic stellate cells and stimulate extracellular matrix synthesis. Hepatology 34, 729-737.

Sergent O, Griffon B, Morel I, Chevanne M, Dubus MP, Cillard P \& Cillard J (1997) Effect of nitric oxide on iron-mediated oxidative stress in primary hepatocyte culture. Hepatology 23, $122-127$.

Shulga N, Hoek JB \& Pastorino JG (2005) Elevated PTEN levels account for the increased sensitivity of ethanol-exposed cells to tumor necrosis factor-induced cytotoxicity. Journal of Biological Chemistry 280, 9416-9424.

Stewart SF, Jones DEJ, Vidali M, Haugk B, Brunt AD, Albano E \& Day CP (2004a) Correlation between antiCYP2E1 titre and lymphocyte infiltration in ALD - an autoimmune disease in some patients. Journal of Hepatology 40, Suppl. 1, 176.

Stewart SF, Leathart JB, Chen Y, Daly AK, Rolla R, Mottaran E, Vay D, Vidali M, Day CP \& Albano E (2002) Valine-alanine manganese superoxide dismutase polymorphism is not associated with alcohol-induced oxidative stress or fibrosis. Hepatology 36, 1355-1360.

Stewart SF, Vidali M, Day CP, Albano E \& Jones DEJ (2004b) Oxidative stress as a trigger for cellular immune response in patients with alcoholic liver disease. Hepatology 39, 197-203.

Stoyanovsky DA \& Cederbaum AI (1998) ESR and HPLC-EC analysis of ethanol oxidation to 1-hydroxyethyl radical: rapid reduction and quantification of POBN and PBN nitroxides. Free Radical Biology and Medicine 25, 536-545. 
Stoyanovsky DA, Wu D \& Cederbaum AI (1998) Interaction of 1-hydroxyethyl radical with glutathione, ascorbic acid and $\alpha$-tocopherol. Free Radical Biology and Medicine 24, $132-138$.

Sutton A, Khoury H, Prop-Buus C, Cepanec C, Pessayre D \& Degoul F (2003) The Ala16Val genetic dimorphism modulates the import of human manganese superoxide dismutase into rat liver mitochondria. Pharmacogenetics 13, 145-157.

Suzuki M, Fujimoto Y, Suzuki Y, Hosoki Y, Saito H, Nakayama $\mathrm{K}$, Ohtake T \& Kohgo Y (2004) Induction of transferrin receptor by ethanol in rat primary hepatocyte culture. Alcoholism, Clinical and Experimental Research 28, 98S-105S.

Takase S, Tsutsumi M, Kawahara H, Takada N \& Takada A (1993) The alcohol-altered liver membrane antibody and hepatitis $\mathrm{C}$ virus infection in the progression of alcoholic liver disease. Hepatology 17, 9-13.

Thiele GM, Freeman TK \& Klassen LW (2004) Immunological mechanisms of alcoholic liver disease. Seminar of Liver Diseases 24, 273-287.

Thurman, RG (1998) Alcoholic liver injury involves activation of Kupffer cells by endotoxins. American Journal of Physiology 275, G605-G611.

Tsukamoto H, French SW, Benson N, Delgado G, Rao GA, Larkin EC \& Largman C (1985) Severe and progressive steatosis and focal necrosis in rat liver induced by continuous intragastric infusion of ethanol and low fat diet. Hepatology $\mathbf{5}$, 224-232.

Tsukamoto H, Horne W, Kamimura S, Niemelä O, Parkkila S, Ylä-Herttuala S \& Brittenham GM (1995) Experimental liver cirrhosis induced by alcohol and iron. Journal of Clinical Investigation 96, 620-630.

Tsukamoto H, Lin M, Ohata M, Giulivi C, French SW \& Brittenham G (1999) Iron primes hepatic macrophages for NF- $\kappa B$ activation in alcoholic liver injury. American Journal of Physiology 277, G1240-G1250.

Uesugi T, Froh M, Arteel GE, Bradford BU \& Thurman RG (2001) Toll-like receptor 4 is involved in the mechanism of early alcohol-induced liver injury in mice. Hepatology 34, 101-108.

Van Pelt FNAM, Straub P \& Manns MP (1995) Molecular basis of drug-induced immunological liver injury. Seminars in Liver Diseases 15, 283-300.

Vay D, Rigamonti C, Vidali M, Mottaran E, Alchera E, Occhino G, Sartori M \& Albano E (2006) Anti-phospholipid antibodies associated with alcoholic liver disease target oxidized phosphatidylserine on apoptotic cell plasma membranes. Journal of Hepatology 44, 183-189.

Vidali M, Hidestrand M, Eliasson E, Mottaran E, Reale E, Rolla R, Occhino G, Albano E \& Ingelman-Sundberg M (2004) Use of molecular simulation for mapping conformational CYP2E1 epitopes. Journal of Biological Chemistry 279, 50949-50955.

Vidali M, Stewart SF, Rolla R, Daly AK, Chen Y, Mottaran E, Jones DEJ, Leathart JB, Day CP \& Albano E (2003) Genetic and epigenetic factors in autoimmune reactions toward cytochrome P4502E1 in alcoholic liver disease. Hepatology 37, 277-285.

Wajant H, Pfizenmaier K \& Scheurich P (2003) Tumor necrosis factor signalling. Cell Death and Differentiation 10, 45-65.

Wheeler MD, Kono H, Yin M, Rusyn I, Froh M, Connor HD, Mason RP, Samulski RJ \& Thurman RG (2001a) Delivery of $\mathrm{Cu} / \mathrm{Zn}$-superoxide dismutase gene with adenovirus reduces early alcohol-induced liver injury in rats. Gastroenterology 120, 1241-1250.

Wheeler MD, Nakagami M, Bradford BU, Uesugi T, Mason RP, Connor HD, Dikalova A, Kadiiska M \& Thurman RG (2001b) Overexpression of manganese superoxide dismutase prevents alcohol-induced liver injury in the rat. Journal of Biological Chemistry 276, 36664-36672.

Yin M, Bradford BU, Wheeler MD, Uesugi T, Froh M, Goyert SM \& Thurman RG (2001) Reduced early alcohol-induced liver injury in CD14-deficient mice. Journal of Immunology 166, 4737-4742.

You M \& Crabb DW (2004) Recent advances in alcoholic liver disease. II. Molecular mechanisms of alcoholic fatty liver. American Journal of Physiology 287, G1-G6.

Zamara E, Novo E, Marra F, Gentilini A, Romanelli RG, Caligiuri A et al. (2004) 4-Hydroxynonenenal as a selective profibrogeneic stimulus for activated human hepatic stellate cells. Journal of Hepatology 40, 60-68.

Ziegler-Heitbrock HW (1995) Molecular mechanism in tolerance to lipopolysaccharide. Journal of Inflammation 45, $13-26$

Ziol M, Tepper M, Lohez M, Arcangeli G, Ganne N, Christidis C, Trinchet JC, Beaugrand M, Guillet JG \& Guettier C (2001) Clinical and biological relevance of hepatocyte apoptosis in alcoholic hepatitis. Journal of Hepatology 34, 254-260. 